\title{
Analysis of the Relationship between Oral Diseases and Glycemic Control of Diabetes in the West African Context: Survey at the Centre Anti-Diabétique d'Abidjan (CADA), Côte d'Ivoire
}

\author{
Jean-Claude Guinan1,2, Guanga David Meless1,2, Abou Dramane Sangaré1,2, Datté Atta Sébastien², \\ Mamadou Samba1,2, Viviane Da-Danho1,2, Ramata Bakayoko-Ly,2
}

${ }^{1}$ Département de Santé Publique, UFROS, UFHB, Abidjan, Côte d'Ivoire

${ }^{2}$ Laboratoire de Santé Publique, Cariologie et Plantes Médicinales, Abidjan, Côte d’Ivoire

Email: ead_dm@yahoo.fr

How to cite this paper: Guinan, J.-C., Meless, G.D., Sangaré, A.D., Sébastien, D.A., Samba, M., Da-Danho, V. and Bakayoko-Ly, R. (2018) Analysis of the Relationship between Oral Diseases and Glycemic Control of Diabetes in the West African Context: Survey at the Centre Anti-Diabétique d'Abidjan (CADA), Côte d'Ivoire. Open Journal of Epidemiology, 8, 213-225.

https://doi.org/10.4236/ojepi.2018.84017

Received: October 24, 2018

Accepted: November 25, 2018

Published: November 28, 2018

Copyright $\odot 2018$ by authors and Scientific Research Publishing Inc. This work is licensed under the Creative Commons Attribution International License (CC BY 4.0).

http://creativecommons.org/licenses/by/4.0/ (c) (i) Open Access

\begin{abstract}
The relationship between diabetes and periodontitis is established and described as a bidirectional influence, whereas that with dental caries is still controversial. The objective of this study was to analyze the relationship between blood glucose control and oral diseases in a population of diabetics followed at the "Centre Anti Diabétique d'Abidjan" (CADA). The dental condition of the diabetics included in this cross-sectional study was assessed by the DMF index, periodontal condition by the CPITN and oral hygiene by the OHIS index. Diabetes data were extracted from CADA patient medical records. Blood glucose control has been defined by an average of the blood glucose values of the last 3 months less than or equal to $1.26 \mathrm{~g} / \mathrm{l}$. Regression models were constructed to estimate the risk of diabetes imbalance adjusted for all characteristics collected. The sample of 356 diabetics consisted of $53.7 \%$ women with an average age of 55.6 years (range: $12-85$ years). The average DMF index was 7.9 (Std: 6.6) with an estimated prevalence of caries of $77.0 \%$, that of periodontitis of $53.1 \%$. The proportion of subjects with good glycemic control was estimated at $41.3 \%$. The characteristics associated with glycemic control were: dry mouth $(\mathrm{p}=0.005)$, type of diabetes treatment ( $\mathrm{p}$ $<0.00014)$ and duration of diabetes $(\mathrm{p}=0.039)$ and periodontal status assessed with the CPITN $(\mathrm{p}=0.014)$. The results of this study confirmed the link between periodontitis and glycemic control of diabetes described in the literature but didn't find significant association between dental caries and
\end{abstract}


diabetes.

\section{Keywords}

Diabetes, Glycemic Control, Oral Health, Periodontitis, Dental Caries, West Africa, Côte d'Ivoire

\section{Introduction}

Diabetes refers to a set of metabolic disorders, both genetically and clinically heterogeneous, characterized by hyperglycemia due to a failure in insulin secretion, its activity or both [1]. Considered as a disease of rich countries for long time, diabetes, especially type 2 diabetes, has become a major public health problem in developing countries, where the increase in the number of cases is higher than the increase in developed countries. Indeed, estimates predict that between 1995 and 2025, the prevalence of adult diabetes will increase by $35 \%$ worldwide, $27 \%$ in developed countries and $82 \%$ in developing countries [2]. In sub-Saharan Africa, the incidence of diabetes is estimated at between $1 \%$ and $6 \%$ of the population and between $6 \%$ and $10 \%$ specifically in South Africa [3]. According to WHO, the number of people affected in Côte d'Ivoire was 264,000 in 2000 and this number will rise to 636,000 by 2030 [4]. In developing countries, industrialization and socio-economic development are certainly the main determinants of the diabetes "epidemic". This is particularly noticeable among urban populations that are becoming westernized and tend to gain weight due to a lack of physical exercise and a change in diet [5] [6] [7] [8] [9]. The main danger of diabetes is that near-permanent hyperglycemia exposes people with vascular complications, with sometimes disabling medical consequences. The complications usually described are: kidney disease, retinopathy, neuropathy, microangiopathy and cardiovascular disease [1] [10] [11]. Oral diseases are among the least cited and monitored diseases in diabetic patients, despite there is growing scientific evidence linking diabetes to these oral diseases [12] [13] [14] [15]. The main oral diseases described in diabetics are: periodontal diseases, dental caries, xérostomia, tooth loss, dental abscesses and oral mucosal lesions [16] [17] [18]. As with most diabetes complications, the prevalence and characteristics of these oral conditions depend on the type of diabetes and the quality of blood glucose control. Several studies describe the oral manifestations of diabetes but very few concern African countries, hence the interest of this survey initiated by the Department of Public Health of the UFR of Odontostomatology of Abidjan, in collaboration with the "Centre Anti-Diabétique d'Abidjan" (CADA), is to study the relationship between oral health and diabetes in the West African context. The objective of this study was to analyze the relationship between glycemic control and oral disease in a population of diabetics followed on an outpatient basis at CADA. 


\section{Methods}

\subsection{Population}

The diabetics included in this cross-sectional study, were recruited at Centre Anti-Diabétique d'Abidjan (CADA), which is the main structure for the management of diabetics in Côte d'Ivoire. The sample of the 472 diabetics included in the initial study was drawn over a period of two months, by a daily draw of about ten subjects from the list of patients who had an appointment at CADA. Diabetics consulting for an emergency, without an appointment, were excluded from the draw. Informed consent was obtained from each patient before the oral clinical examination as previously described [19]. In this analysis, only diabetics with at least two blood glucose measurements at least three months apart, allowing the variable of interest (glycemic control), to be constructed, were included.

\subsection{Data Collection}

Data collection was anonymous, using a questionnaire and an oral clinical examination form. The odontological data were collected during an oral clinical examination performed by a dentist trained for this study. Dental status was assessed from the DMF index, periodontal status from the Community Periodontal Index of Treatment Needs (CPITN), Mülhemann's dental mobility index and oral hygiene from the Oral Hygiene Index Simplified (OHIS). In addition to socio-demographic characteristics, the questionnaire collected information on dental office attendance, oral hygiene habits and the presence of xerostomia. Clinical and biological data related to diabetes such as type of treatment (Hygiene-Dietary Regimen (HDR); Oral Anti Diabetics (OAD); insulin injection), duration of diabetes, as well as biological measurements (blood glucose), were extracted from patients' medical records at CADA.

\subsection{Assessment Criterion for Glycemic Control}

The main marker used to assess glycemic control in diabetics is glycated hemoglobin (HbAlc) which dosage provides an estimation of the glycemic control over a period of about three months [20] [21] [22] [23]. Since it has been established that there is a strong correlation between $\mathrm{HbAlc}$ levels and the average of several blood glucose levels over 12 weeks [24] [25], glycemic control has been defined on the basis of the average blood glucose level over the last 3 months. An average value of the blood glucose measurements over the last 3 months $\leq 1.26$ $\mathrm{g} / \mathrm{l}$ corresponds to good blood glucose control and a value $>1.26 \mathrm{~g} / \mathrm{l}$ corresponds to poor blood glucose control.

\subsection{Data Analysis}

The data were entered on the Epidata software (version 3.1.0.1009) and then analyzed with the SAS statistical software (version 8.2, SAS Institute Inc., Cary, NC, USA). From the calculation of the Body Mass Index $\left(B M I=\right.$ Weight $\left./ S_{i z e}{ }^{2}\right)$ 
the body size was determined according to the classification of the International Obesity Task Force (IOTF) [26]. The duration of diabetes was calculated by differentiating between the date of the oral clinical examination and the date of diagnosis indicated in the CADA medical file. The age was analysed into 4 classes defined by the quartiles. Based on the OHIS score, oral hygiene was defined as follows: Good (OHIS $<1.2)$, Medium $(1.2<$ OHIS < 3.0) and Insufficient (OHIS >3.0). The Mühlemann index defined the presence of dental mobility (Mülhemann >0) or not (Mülhemann $=0$ ). The quantitative variables were described in terms of mean and standard deviation (Std), and the qualitative variables were described in terms of numbers and percentages for each of the modalities. Frequency comparisons were made with the Chi-square test for independent samples and means compararison with the Student test. Logistic regression models were constructed to identify factors associated with glycemic control. Odds Ratio (OR) and their Confidence Intervals (CI) have been calculated to estimate the risks of reciprocal influence between oral disease and glycemic control. All statistical analyses were performed for a risk $\alpha=5 \%$.

\section{Results}

In total, data from 356 diabetics with at least two blood glucose tests to determine glycemic control were analyzed. Table 1 and Table 2 present the description of the sample, which included $53.7 \%$ women with an average age of 55.6

Table 1. Description of the socio-demographic, clinical and odonto-stomatological characteristics of diabetics. Diabetic patients followed at CADA, Abidjan-Côte d'Ivoire. $\mathrm{N}=$ 356.

\begin{tabular}{llcc}
\hline Variables & & $\mathrm{n}$ & $\%$ \\
\hline Sex & Male & 165 & 46.3 \\
& Female & 191 & 53.7 \\
Age (years) & & & \\
& $<48$ & 79 & 22.2 \\
& $48-54$ & 86 & 24.1 \\
& $55-62$ & 96 & 27.0 \\
& $>62$ & 95 & 26.7 \\
Corpulence & & & \\
& Lean & 21 & 5.9 \\
& Normal & 151 & 42.4 \\
& Overweight & 135 & 37.9 \\
& Obese & 49 & 13.8 \\
Dental consultation after diabetes diagnosis & Yes & & \\
& No & 93 & 26.1 \\
Oral hygiene & & 263 & 73.9 \\
& Good & & \\
\hline & & 12 & 3.4 \\
\hline
\end{tabular}




\section{Continued}

\begin{tabular}{lcc}
\hline Medium & 62 & 17.8 \\
Insufficient & 275 & 78.8
\end{tabular}

Xerostomia

$\begin{array}{lll}\text { Yes } & 156 & 43.8 \\ \text { No } & 200 & 56.5\end{array}$

Type of diabetes treatment

$\begin{array}{lcc}\text { HDR } & 27 & 7.6 \\ \text { HDR + OAD } & 102 & 28.6 \\ \text { HDR + OAD + Insuline } & 227 & 63.8\end{array}$

Duration of diabetes (years)

$\begin{array}{lcc}<1 & 30 & 8.4 \\ 1-4 & 161 & 45.2 \\ 5-10 & 81 & 22.8 \\ >10 & 84 & 23.6\end{array}$

Glycemic control

Yes(Glycemia $\leq 1.26 \mathrm{~g} / \mathrm{l})$

41.3

No (Glycemia $>1.26 \mathrm{~g} / \mathrm{l})$

$147 \quad 41.3$

$209-58.7$

CPITN

$\begin{array}{lcc}\text { Healthy } & 0 & 0 \\ \text { Bleeding on probing } & 0 & 0 \\ \text { Calculus } & 164 & 46.9 \\ \text { Pocket } 4 \text { - } 5 \mathrm{~mm} & 141 & 40.3 \\ \text { Pocket }>6 \mathrm{~mm} & 45 & 12.8\end{array}$

Dental mobility

$\begin{array}{lll}\text { Yes } & 168 & 47.2\end{array}$

No $\quad 188 \quad 52.8$

Dental caries

$\begin{array}{lcc}\text { Yes } & 274 & 77.0 \\ \text { No } & 82 & 33.0\end{array}$

Periodontitis

$\begin{array}{lll}\text { Yes } & 186 & 53.1 \\ \text { No } & 170 & 46.9\end{array}$

HDR: Hygiene Dietary Regime, OAD: Oral Anti Diabetics, CPITN: Community Periodontal Index of Treatment Needs.

Table 2. Description of the dental condition from the index of decayed, missing or filled teeth (DMF index). Diabetic patients followed at CADA, Abidjan-Côte d'Ivoire. $\mathrm{N}=356$.

\begin{tabular}{cccc}
\hline & Mean (\%) & Std & Min-Max \\
\hline Decayed & $2.97(37.7 \%)$ & 3.22 & $0-23$ \\
Missing & $4.75(60.3)$ & 6.05 & $0-32$ \\
Filled & $0.16(2.0)$ & 0.64 & $0-6$ \\
DMF index & $7.88(100)$ & 6.59 & $0-32$ \\
\hline
\end{tabular}


years (range: 12 - 85 years). Less than half of the sample (42.4\%) had normal corpulence, $5.9 \%$ were lean, $37.9 \%$ overweight and $13.8 \%$ obese. Only $26.1 \%$ had seen a dentist since the diagnosis of diabetes. The duration of diabetes ranged from 6 months to 26 years, with more than half of the subjects (53.6\%) having less than 5 years of seniority and $23.6 \%$ having more than 10 years of seniority. Glycemic control was found in $41.3 \%$ of diabetics at the time of the survey. No subjects had healthy gums without bleeding on the survey. The presence of tartar was found in $46.9 \%$ of subjects, $40.3 \%$ had at least one periodontal pocket of 4 to $5 \mathrm{~mm}$ and $12.8 \%$ had at least one periodontal pocket of $6 \mathrm{~mm}$ or more (Table 1). The mean DMFT index was 7.9 (standard deviation: 6.6) with a high prevalence of the Filled index component (60.3\%) (Table 2). The prevalence of dental caries was estimated at $77.0 \%$, periodontitis at $53.1 \%$ and dental mobility at $47.2 \%$. The proportion of subjects with good glycemic control was estimated at $41.3 \%$ (Table 1). The characteristics associated with glycemic control were: xerostomia $(p=0.005)$, type of diabetes treatment $(p<0.00014)$, duration of diabetes $(p=$ $0.039)$ and periodontal status assessed with the CPITN index ( $\mathrm{p}=0.014)$ (Table 3 and Table 4). The risk of poor glycemic control increased by $66 \%$ when the duration of diabetes increases by 1 year $(\mathrm{OR}=1.66$; $95 \% \mathrm{CI}=[1.40-2.65])$. Diabetics with HDR and OAD are 14 times more likely to have a diabetes imbalance than those with only HDR $(\mathrm{OR}=14.07 ; 95 \% \mathrm{CI}=[4.40-45.02])$. Diabetics with diabetes who have in addition to diet and OAD, insulin have 7.37 times more risk of diabetes imbalance than those with only $\mathrm{HDR}(\mathrm{OR}=7.37 ; 95 \% \mathrm{CI}=$ [2.43 - 22.34]). The presence of periodontal pockets of $6 \mathrm{~mm}$ and more increases the risk of poor glycemic control. Patients with deep periodontal pockets are 2.5 times more likely than those with only $\operatorname{tartar}(\mathrm{OR}=2.46$; $95 \% \mathrm{CI}=[1.10-5.49])$. Risk of unbalanced diabetes was 1.88 times higher in diabetics with a feeling of xerostomia than in others $(\mathrm{OR}=1.88 ; 95 \% \mathrm{CI}=[1.18-2.98])$ (Table 5).

Table 3. Sociodemographic and diabetes characteristics associated with glycemic control. Logistic regression models. Diabetic patients followed at CADA, Abidjan-Côte d'Ivoire. N $=356$.

\begin{tabular}{|c|c|c|c|c|}
\hline & \multirow{3}{*}{ Variables } & \multicolumn{2}{|c|}{ Glycemic control } & \multirow{3}{*}{ p } \\
\hline & & $\begin{array}{c}\text { Glycemia } \leq 1.26 \mathrm{~g} / 1 \\
(\mathrm{~N}=147)\end{array}$ & $\begin{array}{c}\text { Glycemia }>1.26 \mathrm{~g} / 1 \\
(\mathrm{~N}=209)\end{array}$ & \\
\hline & & $\mathrm{n}(\%)$ & $\mathrm{n}(\%)$ & \\
\hline \multirow[t]{3}{*}{ Sex } & & & & 0.851 \\
\hline & Male & $69(41.8)$ & $96(58.2)$ & \\
\hline & Female & $78(40.8)$ & $113(59.2)$ & \\
\hline \multirow[t]{5}{*}{ Age (Years) } & & & & 0.291 \\
\hline & $<48$ & $36(45.6)$ & $43(54.4)$ & \\
\hline & $48-54$ & $36(41.9)$ & $50(58.1)$ & \\
\hline & $55-62$ & $32(33.3)$ & $64(66.7)$ & \\
\hline & $>62$ & $43(45.3)$ & $52(54.7)$ & \\
\hline Corpulence & & & & 0.341 \\
\hline
\end{tabular}




\section{Continued}

\begin{tabular}{lccc}
\hline Lean & $6(28.6)$ & $15(71.4)$ & \\
Normal & $69(45.7)$ & $82(54.3)$ & \\
Overweight & $51(37.8)$ & $84(62.2)$ & \\
Obese & $21(42.9)$ & $28(57.1)$ & \\
Type of diabetes treatment & & & 0.00014 \\
HDR & $23(85.2)$ & $4(14.8)$ & \\
HDR + OAD & $28(27.5)$ & $74(72.5)$ & \\
HDR + OAD + Insulin & $96(42.3)$ & $131(57.7)$ & \\
Duration of diabetes (Years) & & & \\
$<1$ & $8(26.7)$ & $22(73.3)$ & \\
$1-4$ & $79(49.1)$ & $82(50.9)$ & \\
$5-10$ & $30(37.0)$ & $51(63.0)$ & \\
$>10$ & $30(35.7)$ & $54(64.3)$ & \\
\hline
\end{tabular}

Table 4. Oral diseases and odonto-stomatological characteristics associated with glycemic control. Logistic regression models. Diabetic patients followed at CADA, Abidjan-Côte d'Ivoire. $\mathrm{N}=356$.

\begin{tabular}{|c|c|c|c|c|}
\hline & \multirow{3}{*}{ Variables } & \multicolumn{2}{|c|}{ Glycemic control } & \multirow{3}{*}{$\mathrm{p}$} \\
\hline & & $\begin{array}{c}\text { Glycemia } \leq 1.26 \mathrm{~g} / 1 \\
(\mathrm{~N}=147)\end{array}$ & $\begin{array}{c}\text { Glycemia }>1.26 \mathrm{~g} / \mathrm{l} \\
\quad(\mathrm{N}=209)\end{array}$ & \\
\hline & & $\mathrm{n}(\%)$ & $\mathrm{n}(\%)$ & \\
\hline \multicolumn{4}{|c|}{ Dental consultation after diabetes diagnosis } & 0.294 \\
\hline & Yes & $35(37.6)$ & $58(62.4)$ & \\
\hline & No & $112(76.2)$ & $151(72.2)$ & \\
\hline \multicolumn{4}{|l|}{ Oral hygiene } & 0.831 \\
\hline & Good & $4(1.2)$ & $8(2.3)$ & \\
\hline & Medium & $25(7.2)$ & $37(10.6)$ & \\
\hline & Insufficient & $115(42.6)$ & $160(57.4)$ & \\
\hline \multicolumn{4}{|l|}{ Xerostomia } & 0.005 \\
\hline & Yes & $51(32.7)$ & $105(67.3)$ & \\
\hline & No & $96(48.0)$ & $104(52.0)$ & \\
\hline \multicolumn{4}{|l|}{ CPITN } & 0.014 \\
\hline & Healthy & $0(0.0)$ & $0(0.0)$ & \\
\hline & Bleeding on probing & $0(0.0)$ & $0(0.0)$ & \\
\hline & Calculus & $68(41.5)$ & $96(58.5)$ & \\
\hline & Pocket $4-5 \mathrm{~mm}$ & $66(46.8)$ & $75(53.2)$ & \\
\hline & Pocket $>6 \mathrm{~mm}$ & $10(22.2)$ & $35(77.8)$ & \\
\hline \multicolumn{5}{|c|}{ Indices de caries } \\
\hline & Decayed & $2.9(3.3)$ & $3.0(3.2)$ & 0.866 \\
\hline & Missing & $4.8(6.3)$ & $4.7(5.9)$ & 0.848 \\
\hline & Filled & $0.2(0.7)$ & $0.2(0.6)$ & 0.861 \\
\hline & DMF index & $7.9(6.7)$ & $7.8(6.5)$ & 0.912 \\
\hline
\end{tabular}

CPITN: Community Periodontal Index of Treatment Needs. 
Table 5. Estimation of the risk of poor glycemic control based on the clinical and Odonto-stomatological characteristics associated with glycemic control. Logistic regression models. Diabetic patients followed at CADA, Abidjan-Côte d'Ivoire. $\mathrm{N}=356$.

\begin{tabular}{lcccc}
\hline & \multicolumn{3}{c}{ Logistic regression model } & \multirow{2}{*}{ P } \\
\cline { 2 - 4 } & Coef. $\beta$ & OR $_{\text {ajust }}$ & CI $_{95 \%}$ & \\
\hline $\begin{array}{l}\text { Duration of diabetes (Years) } \\
\text { Type of diabetes treatment }\end{array}$ & 0.51 & 1.66 & {$[1.40-2.65]$} & 0.022 \\
$\quad$ Régime Hygiéno-Diététique & - & - & - & 0.0001 \\
HDR + OAD & 2.64 & 14.07 & {$[4.40-45.02]$} & \\
HDR + OAD + Insuline & 1.99 & 7.37 & {$[2.43-22.34]$} & \\
CPITN & & & & 0.018 \\
$\quad$ Calculus & - & - & & \\
$\quad$ Pocket $4-5 \mathrm{~mm}$ & -0.21 & 0.81 & {$[0.50-1.30]$} & \\
$\quad$ Pocket $>6$ mm & 0.90 & 2.46 & {$[1.10-5.49]$} & \\
Xerostomia & 0.63 & 1.88 & {$[1.18-2.98]$} & 0.005 \\
\hline
\end{tabular}

HDR: Hygiene Dietary Regime, OAD: Oral Anti Diabetics, CPITN: Community Periodontal Index of Treatment Needs.

\section{Discussion}

Diabetes is a chronic metabolic disease associated with many systemic and oral manifestations such as dental caries, salivary dysfunction, oral mucosal infections and other oral infections, taste disorders and neurosensory disorders, gingivitis, periodontitis, etc. [27]. While in the scientific literature, the relationship between diabetes and periodontitis is established and described as a mutual influence, which with dental caries is still controversial. In this study, we analyzed the relationship between the glycemic control of diabetes and the 2 main oral diseases such as periodontitis and dental caries. The method of sample selection, by daily draw over a period of two months at the main diabetes monitoring center in Côte d'Ivoire, as well as the collection of data by a standardized questionnaire administered by a single practitioner [19], made it possible to minimize potentiel selection and information bias. The results of this study highlighted an association between glycemic control and periodontitis with an estimated risk of poor diabetes control of 2.5 in subjects with periodontal pockets of $6 \mathrm{~mm}$ and more. This is consistent with the findings of the recent literature review by Graziani et al. published in 2018 [27]. In our study, the risk of poor glycemic control was estimated according to the level of periodontal disease using as a reference group, diabetics having no periodontal pockets. The adjusted odds ratio (ORaj) on diabetes characteristics estimated for the association between periodontitis and glycemic control was 2.46 ( $\mathrm{p}<0.018$ ), thus confirming the association between diabetes and periodontal disease, described and confirmed in numerous studies conducted in several countries around the world [27] [28] [29] [30] [31]. The effectiveness of periodontal therapies in improving glycemic control, re- 
ported in several studies with a high level of scientific evidence, is an argument that supports the hypothesis of a negative influence of periodontitis on the balance of diabetes [32] [33] [34] [35] [36]. Just as diabetes increases patients' susceptibility to periodontal disease, periodontal disease, with the inflammation it maintains in the oral cavity, increases insulin resistance through proinflammatory cytokines [37]. The relationship between diabetes and periodontitis is an indisputable two-way relationship in which the two conditions support each other [38] [39] [40] unlike the relationship between tooth decay and diabetes. In our study, despite the high prevalence of caries (77\%) and the estimated DMFT index of 7.9 teeth, the link between diabetes glycemic control and dental caries has not been established. Indeed, neither of these two indicators of dental caries was associated with diabetic balance. The prevalence of caries observed was similar between balanced and unbalanced diabetics and there was no significant association between caries indices and the level of diabetes equilibrium. The DMF index was 7.9 in patients with controlled diabetes and 7.8 in patients with uncontrolled diabetes. These results are in agreement with Collin et al. [41] and Edblad et al. [42] who didn't find a relationship between tooth decay and diabetes balance, but in total contradiction with Twetman's study, which showed that diabetics with poor glycemic control developed three times more carious lesions than those with better glycemic control [43]. This statement is supported by Satoru et al. who found a significant association between the number of decayed teeth and high levels of glycosylated hemoglobin (HbA1c) [44], which is the main marker of glycemic control in diabetes. Although the data on the relationship between dental caries and diabetes are still contradictory, it is clear that oral environmental disturbances induced by high blood sugar levels, such as a disruption of the oral flora in favour of cariogenic bacteria, a decrease in $\mathrm{pH}$ and salivary flow, changes in the composition of saliva, which thus loses its protective powers (anti-infectious and against caries) within the oral cavity, as well as high concentrations of glucose in saliva and gingival fluid in these patients are likely to increase the risk of dental caries [45] [46]. It is the oral environment favourable to oral diseases that justifies the recommendation for follow-up visits to the dentist every 6 months [47] to prevent the development of new dental lesions and periodontal diseases. In our study, only one in four diabetics (26.1\%) has seen a dentist since the diagnosis of diabetes. It should be noted that in Côte d'Ivoire, and particularly at CADA, the follow-up of diabetic patients does not include systematic oral check-ups, as is the case for most other organs targeting diabetes complications such as the eyes, heart, kidneys, etc.

\section{Conclusion}

The results of this study confirmed the association between periodontitis and glycemic control of diabetes but did not show a significant association between dental caries and diabetes. However, given the evidence of cariogenic salivary conditions described in diabetics, health professionals in Côte d'Ivoire should 
systematically inform diabetic patients about the link between oral health and diabetes on the one hand, and on the other hand, sensitize them to make at least one visit every 6 months to the dentist.

\section{Conflicts of Interest}

The authors declare no conflicts of interest regarding the publication of this paper.

\section{References}

[1] The Experts Committee on the Diagnosis and Classification of Diabetes Mellitus (2003) Report of the Expert Committee on the Diagnosis and Classification of Diabetes Mellitus. Diabetes Care, 26, 5-20. https://doi.org/10.2337/diacare.26.2007.S5

[2] King, H., Aubert, R.E. and Herman, W.H. (1998) Global Burden of Diabetes, 1995-2025: Prevalence, Numerical Estimates, and Projections. Diabetes Care, 21, 1414-1431. https://doi.org/10.2337/diacare.21.9.1414

[3] Sobngwi, E., Mauvais-Jarvis, F., Vexiau, P., Mbanya, J.C. and Gautier, J.F. (2001) Diabetes in Africans. Part 1: Epidemiology and Clinical Specificities. Diabetes \& Metabolism, 27, 628-634.

[4] Wild, S., Roglic, G., Green, A., Sicree, R. and King, H. (2004) Global Prevalence of Diabetes: Estimates for the Year 2000 and Projections for 2030. Diabetes Care, 27, 1047-1053. https://doi.org/10.2337/diacare.27.5.1047

[5] Gadsby, R. (2002) Epidemiology of Diabetes. Advanced Drug Delivery Reviews, 54, 1165-1172. https://doi.org/10.1016/S0169-409X(02)00094-7

[6] Tuomilehto, J., Lindstrom, J., Eriksson, J.G., Valle, T.T., Hamalainen, H., Ilanne-Parikka, P., Keinanen-Kiukaanniemi, S., Laakso, M., Louheranta, A., Rastas, M., Salminen, V. and Uusitupa, M. (2001) Prevention of Type 2 Diabetes Mellitus by Changes in Lifestyle among Subjects with Impaired Glucose Tolerance. New England Journal of Medicine, 344, 1343-1350. https://doi.org/10.1056/NEJM200105033441801

[7] Simon, D., Bourgeon, M., Balkau, B., Eschwege, E. and Charles, M.A. (2001) Insulin Sensitivity and Ethnic Groups. Diabetes \& Metabolism, 27, 215-221.

[8] M Hernández Ruiz de Eguilaz, M., Batlle, M.A., Martínez de Morentin, B., San-Cristóbal, R., Pérez-Díez, S., Navas-Carretero, S. and Martínez, J.A. (2016) Alimentary and Lifestyle Changes as a Strategy in the Prevention of Metabolic Syndrome and Diabetes Mellitus Type 2: Milestones and Perspectives. Anales del Sistema Sanitario de Navarra, 39, 269-289.

[9] Grégoire, J. and Philis, M.G. (2017) The Nutritional Education of Patients with Diabetes. Soins, 62, 19-23. https://doi.org/10.1016/j.soin.2017.03.006

[10] Barrett, E.J., Liu, Z., Khamaisi, M., King, G.L., Klein, R., Klein, B.E.K., Hughes, T.M., Craft, S., Freedman, B.I., Bowden, D.W., Vinik, A.I. and Casellini, C.M. (2017) Diabetic Microvascular Disease: An Endocrine Society Scientific Statement. The Journal of Clinical Endocrinology and Metabolism, 102, 4343-4410. https://doi.org/10.1210/jc.2017-01922

[11] Orchard, T.J., Dorman, J.S., Maser, R.E., Becker, D.J., Drash, A.L., Ellis, D., Laporte, R.E. and Kuller, L.H. (1990) Prevalence of Complications in IDDM by Sex and Duration. Pittsburgh Epidemiology of Diabetes Complications Study II. Diabetes, 39, 1116-1124. https://doi.org/10.2337/diab.39.9.1116

[12] Wallet, S.M., Puri, V. and Gibson, F.C. (2018) Linkage of Infection to Adverse Sys- 
temic Complications: Periodontal Disease, Toll-Like Receptors, and Other Pattern Recognition Systems. Vaccines (Basel), 6, 21.

https://www.mdpi.com/2076-393X/6/2/21 https://doi.org/10.3390/vaccines6020021

[13] Kudiyirickal, M.G. and Pappachan, J.M. (2015) Diabetes Mellitus and Oral Health. Endocrine, 49, 27-34. https://doi.org/10.1007/s12020-014-0496-3

[14] Kathiresan, T.S., Masthan, K., Sarangarajan, R., Babu, N.A. and Kumar, P. (2017) A Study of Diabetes Associated Oral Manifestations. Journal of Pharmacy \& Bioallied Sciences, 9, 211-216. https://doi.org/10.4103/jpbs.JPBS_157_17

[15] Mauri-Obradors, E., Estrugo-Devesa, A., Jané-Salas, E., Viñas, M. and López-López, J. (2017) Oral Manifestations of Diabetes Mellitus. A Systematic Review. Medicina Oral Patologia Oral Cirugia Bucal, 22, 586-594.

https://doi.org/10.4317/medoral.21655

[16] Ternois, M. (2017) The Oral Cavity: A Mirror of Diabetes. Presse Médicale, 46, 822-830. https://doi.org/10.1016/j.lpm.2017.04.001

[17] Trentin, M.S., Verardi, G., De C Ferreira, M., de Carli, J.P., da Silva, S.O., Lima, I.F. and Paranhos, L.R. (2017) Most Frequent Oral Lesions in Patients with Type 2 Diabetes Mellitus. The Journal of Contemporary Dental Practice, 18, 107-111. https://doi.org/10.5005/jp-journals-10024-1999

[18] Darnell, J.A. and Saunders, M.J. (1990) Oral Manifestations of the Diabetic Patient. Texas Dental Journal, 107, 23-27.

[19] Meless, G.D., Guinan, J.-C., Adouéni, K.V., Giumelli, B., Maurice-Tison, S., Bakayoko-Ly, R. and Soueidan, A. (2007) Epidemiologic Enquiry Concerning the Oro-Dental Condition and Monitoring of Diabetic Patients in Ivory Coast. Odontostomatologie Tropicale, 30, 15-22.

[20] Bunn, H.F., Gabbay, K.H. and Gallop, P.M. (1978) The Glycosylation of Hemoglobin: Relevance to Diabetes Mellitus. Science, 200, 21-27. https://doi.org/10.1126/science.635569

[21] Davidson, M.B., Schriger, D.L., Peters, A.L. and Lorber, B. (2000) Revisiting the Oral Glucose Tolerance Test Criterion for the Diagnosis of Diabetes. Journal of General Internal Medicine, 15, 551-555. https://doi.org/10.1046/j.1525-1497.2000.08024.x

[22] Gonen, B., Rubenstein, A., Rochman, H., Tanega, S.P. and Horwitz, D.L. (1977) Haemoglobin A1: An Indicator of the Metabolic Control of Diabetic Patients. The Lancet, 2, 734-737. https://doi.org/10.1016/S0140-6736(77)90237-9

[23] Koenig, R.J., Peterson, C.M., Jones, R.L., Saudek, C., Lehrman, M. and Cerami, A. (1976) Correlation of Glucose Regulation and Hemoglobin AIc in Diabetes Mellitus. The New England Journal of Medicine, 295, 417-420. https://doi.org/10.1056/NEJM197608192950804

[24] Makris, K., Spanou, L., Rambaouni-Antoneli, A., Koniari, K., Drakopoulos, I., Rizos, D. and Haliassos, A. (2008) Relationship between Mean Blood Glucose and Glycated Haemoglobin in Type 2 Diabetic Patients. Diabetic Medicine, 25, 174-178. https://doi.org/10.1111/j.1464-5491.2007.02379.x

[25] Makulo, J.R., Nseka, N.M., Lepira, F.B., Bieleli, E. and Nge, O.A. (2010) Correlation between Capillary Fasting Glucose and HbA1c: Study on 181 Type 2 Diabetics Patients in Democratic Republic of the Congo. Medecine Tropical, 70, 513-516.

[26] Cole, T.J., Bellizzi, M.C., Flegal, K.M. and Dietz, W.H. (2000) Establishing a Standard Definition for Child Overweight and Obesity Worldwide: International Survey. BMJ, 320, 1240-1243. https://doi.org/10.1136/bmj.320.7244.1240 
[27] Graziani, F., Gennai, S., Solini, A. and Petrini, M. (2018) A Systematic Review and Meta-Analysis of Epidemiologic Observational Evidence on the Effect of Periodontitis on Diabetes: An Update of the EFP-AAP Review. Journal of Clinical Periodontology, 45, 167-187. https://doi.org/10.1111/jcpe.12837

[28] Lamster, I.B., Lalla, E., Borgnakke, W.S. and Taylor, G.W. (2008) The Relationship between Oral Health and Diabetes Mellitus. Journal of American Dental Association, 139, 19S-24S. https://doi.org/10.14219/jada.archive.2008.0363

[29] Nazir, M.A., AlGhamdi, L., AlKadi, M., AlBeajan, N., AlRashoudi, L. and AlHussan, M. (2018) The Burden of Diabetes, Its Oral Complications and Their Prevention and Management. Open Access Macedonian Journal of Medical Sciences, 6, 1545-1553. https://doi.org/10.3889/oamjms.2018.294

[30] Stanko, P. and Izakovicova Holla, L. (2014) Bidirectional Association between Diabetes Mellitus and Inflammatory Periodontal Disease. A Review. Biomedical Papers of the Medical Faculty of the University Palacky Olomouc Czechoslovakia, 158, 35-38. https://doi.org/10.5507/bp.2014.005

[31] Taylor, G.W. and Borgnakke, W.S. (2008) Periodontal Disease: Associations with Diabetes, Glycemic Control and Complications. Oral Diseases, 14, 191-203. https://doi.org/10.1111/j.1601-0825.2008.01442.x

[32] Mauri-Obradors, E., Jané-Salas, E., Sabater-Recolons, M.M., Vinas, M. and López-López, J. (2015) Effect of Nonsurgical Periodontal Treatment on Glycosylated Hemoglobin in Diabetic Patients: A Systematic Review. Odontology, 103, 301-313. https://doi.org/10.1007/s10266-014-0165-2

[33] Artese, H.P., Foz, A.M., Rabelo Mde, S., Gomes, G.H., Orlandi, M., Suvan, J., D’Aiuto, F. and Romito, G.A. (2015) Periodontal Therapy and Systemic Inflammation in Type 2 Diabetes Mellitus: A Meta-Analysis. PLoS ONE, 10, e0128344. https://doi.org/10.1371/journal.pone.0128344 https://journals.plos.org/plosone/article?id=10.1371/journal.pone.0128344

[34] Simpson, T.C., Weldon, J.C., Worthington, H.V., Needleman, I., Wild, S.H., Moles, D.R., Stevenson, B., Furness, S. and Iheozor-Ejiofor, Z. (2015) Treatment of Periodontal Disease for Glycaemic Control in People with Diabetes Mellitus. The Cochrane Database of Systematic Reviews, 6, CD004714.

https://www.cochranelibrary.com/cdsr/doi/10.1002/14651858.CD004714.pub3/full https://doi.org/10.1002/14651858.CD004714.pub3

[35] Kiran, M., Arpak, N., Unsal, E. and Erdogan, M.F. (2005) The Effect of Improved Periodontal Health on Metabolic Control in Type 2 Diabetes Mellitus. Journal of Clinical Periodontology, 32, 266-272. https://doi.org/10.1111/j.1600-051X.2005.00658.x

[36] Rodrigues, D.C., Taba, M.J., Novaes, A.B., Souza, S.L. and Grisi, M.F. (2003) Effect of Non-Surgical Periodontaltherapy on Glycemic Control in Patients with Type 2 Diabetes Mellitus. Journal Periodontology, 74, 1361-1367. https://doi.org/10.1902/jop.2003.74.9.1361

[37] Mealey, B.L. and Oates, T.W. (2006) Diabetes Mellitus and Periodontal Diseases. Journal of Periodontology, 77, 1289-1303. https://doi.org/10.1902/jop.2006.050459

[38] Mealey, B.L. (2006) Periodontal Disease and Diabetes. A Two-Way Street. Journal of the American Dental Association, 137, 26-31. https://doi.org/10.14219/jada.archive.2006.0404

[39] Taylor, G.W. (2001) Bidirectional Interrelationships between Diabetes and Periodontal Diseases: An Epidemiologic Perspective. Annals of Periodontology, 6, 99-112. https://doi.org/10.1902/annals.2001.6.1.99 
[40] Almas, K., Al-Qahtani, M., Al-Yami, M. and Khan, N. (2001) The Relationship between Periodontal Disease and Blood Glucose Level among Type II Diabetic Patients. The Journal of Contemporary Dental Practice, 2, 18-25.

[41] Collin, H.L., Uusitupa, M., Niskanen, L., Koivisto, A.M., Markkanen, H. and Meurman, J.H. (1998) Caries Inpatients with Non-Insulin-Dependent Diabetes Mellitus. Oral Surgery Oral Medicine Oral Pathology Oral Radiology Endodontics, 85, 680-685. https://doi.org/10.1016/S1079-2104(98)90035-X

[42] Edblad, E., Lundin, S.A., Sjödin, B. and Aman, J. (2001) Caries and Salivary Status in Young Adults with Type 1 Diabetes. Swedish Dental Journal, 25, 53-60.

[43] Twetman, S., Johansson, I., Birkhed, D. and Nederfors, T. (2002) Caries Incidence in Young Type 1 Diabetes Mellitus Patients in Relation to Metabolic Control and Caries-Associated Risk Factors. Caries Research, 36, 31-35.

https://doi.org/10.1159/000057587

[44] Yonekura, S., Usui, M. and Murano, S. (2017) Association between Numbers of Decayed Teeth and HbA1c in Japanese Patients with Type 2 Diabetes Mellitus. Upsala Journal of Medical Sciences, 122, 108-113. https://doi.org/10.1080/03009734.2017.1285838

[45] Ciglar, I., Sutalo, J., Sjaljac-Staudt, G. and Bozikov, J. (1991) Saliva as a Risk Factor for Caries in Diabetic Patients. Acta Stomatologica Croatica, 25, 143-149.

[46] Carda, C., Carranza, M., Arriaga, A., Díaz, A., Peydró, A. and Gomez de Ferraris, M.E. (2006) Structural and Functional Salivary Disorders in Type 2 Diabetic Patients. Medicina Oral Patologia Oral y Cirugia Bucal, 11, 309-314.

[47] ANAES (1999) Medical Recommendations and References about Follow-Up of Class 2 Diabetic Patient Excluding Complications. Journal des Maladies Vasculaires, 24, 239-244. 